\title{
Spanish validation of the Sexual Addiction Screening Test
}

\author{
JESÚS CASTRO-CALVO ${ }^{1,2 *}$, RAFAEL BALLESTER-ARNAL ${ }^{1}$, JOEL BILLIEUX ${ }^{2}$, BEATRIZ GIL-JULIÁ ${ }^{3}$ and \\ MARÍA DOLORES GIL-LLARIO ${ }^{4}$ \\ ${ }^{1}$ Salusex-Unisexsida, Departamento de Psicología Básica, Clínica y Psicobiología, Facultad de Ciencias de la Salud, \\ Universitat Jaume I, Castellón, Spain \\ ${ }^{2}$ Addictive and Compulsive Behaviours Lab, Institute for Health and Behaviour, University of Luxembourg, Esch-sur-Alzette, Luxembourg \\ ${ }^{3}$ Departamento de Personalidad, Evaluación y Tratamientos Psicológicos, Universitat de València, Estudi General, Spain \\ ${ }^{4}$ Departamento de Psicología Evolutiva y de la Educación, Universitat de València, Estudi General, Spain
}

(Received: March 11, 2018; revised manuscript received: May 22, 2018; accepted: May 28, 2018)

\begin{abstract}
Background and aims: Sexual addiction is a pathological behavior characterized by a combination of excessive sexual desire and impaired ability to control it. Its incidence ranges between $1.2 \%$ and $32.2 \%$, although this number may vary depending on the screening tool used. This wide variability is largely due to the use of non-validated instruments (e.g., structural validity relying on exploratory analyses, instruments translated without an additional validation process, or instruments validated in another format). To deal with these limitations, this study tested the psychometric properties of the Spanish paper-and-pencil and online versions of the Sexual Addiction Screening Test (SAST). Methods: A total of 2,528 participants (1,163 males) completed the Spanish version of the SAST, along with other instruments assessing sexual compulsivity $(1,585=$ paper-and-pencil, $943=$ online $)$. Results: The exploratory factor analysis yielded a four-factor structure explaining $57.39 \%$ of the variance for the SAST paper-and-pencil version. This factor structure was then verified for the online version through the use of confirmatory factor analysis $\left[\chi^{2}(264)=441.59 ; \chi^{2} / d f=1.66 ;\right.$ RMSEA $\left.=0.02 ; \mathrm{CFI}=0.94 ; \mathrm{IFI}=0.94\right]$. This methodology was also used to support measurement invariance (configural, metric, and scalar invariance) according to gender. The reliability of the total score ranged from .82 to .85 . Similarly, correlations with related scales were positive and significant ( $r$ between .22 and .71). Temporal stability 1 year after the first application was 0.65 (paper-and-pencil format) and 0.60 (online version). Conclusion: These results, together with the absence of questionnaires translated into Spanish to assess this construct, justify the use of the SAST in the evaluation of sexual addiction in Spanish-speaking countries.
\end{abstract}

Keywords: Sexual Addiction Screening Test (SAST), Spanish validation, psychometric properties, compulsive sexual behavior, hypersexuality

\section{INTRODUCTION}

Sex addiction (also called sexual compulsivity or hypersexuality) is a pathological behavior characterized by a combination of excessive sexual desire - expressed through normophilic fantasies, impulses, and/or sexual behaviors and impaired ability to control it (Kafka, 2013; Walters, Knight, \& Långström, 2011). The most common manifestations include compulsive masturbation, abusive use of online sexual activities (e.g., pornography or sexual webcams), incessant search for new sexual partners, and/or compulsive sex with a stable partner (Karila et al., 2014; Wéry et al., 2016). According to McBride, Reece, and Sanders (2008), compulsive sexual behavior is functionally impairing and has a negative impact on various aspects of daily living (e.g., medical, financial, legal, psychological, social, and spiritual). Couple problems are commonly reported (present in $56.2 \%$ of these patients; Spenhoff, Kruger, Hartmann, \& Kobs, 2013) along with various psychological problems (e.g., poor self-esteem, negative affect, guilt, and shame) (Reid, Harper, \& Anderson, 2009).
Although no consensus exists regarding the conceptualization of sex addiction (Wéry \& Billieux, 2017), common criteria used to diagnose this pathological behavior include (a) excessive time and effort spent on sexual activity; (b) impaired selfcontrol; (c) systematic failure to fulfill family, social, or work responsibilities; and (d) persistence in the sexual behavior despite its consequences. Inspired by the criteria used in substance-use disorders, some authors include tolerance, abstinence, and craving as common symptoms among individuals with sexual addiction (Allen, Kannis-Dymand, \& Katsikitis, 2017; Rosenberg, Carnes, \& O'Connor, 2014). However, the applicability of these criteria to behavioral addictions is still under debate (King, Herd, \& Delfabbro, 2017; Starcevic, 2016).

Based on screening scales, the prevalence of excessive sexual behavior ranges from $3 \%$ to $17.4 \%$ in men and from

\footnotetext{
* Corresponding author: Jesús Castro-Calvo; Salusex-Unisexsida, Departamento de Psicología Básica, Clínica y Psicobiología, Facultad de Ciencias de la Salud, Universidad Jaume I, s/n Vicent Sos Baynat, Castellón de la Plana 12071, Spain; Phone: +34 964 729709; Fax: +34 964 729267; E-mail: castro@uji.es
}

This is an open-access article distributed under the terms of the Creative Commons Attribution-NonCommercial 4.0 International License, which permits unrestricted use, distribution, and reproduction in any medium for non-commercial purposes, provided the original author and source are credited, a link to the CC License is provided, and changes - if any - are indicated. 
$1.2 \%$ to $32.2 \%$ in women (Odlaug et al., 2013; Odlaug \& Grant, 2010; Rettenberger, Klein, \& Briken, 2015; Seegers, 2003). These wide ranges reflect the enormous variability in available screening scales and call for caution when using such instruments as diagnostic tools. In a review of the main instruments used to assess sex addiction symptoms, Hook, Hook, Davis, Worthington, and Penberthy (2010) point out some of the problems that compromise the reliability of the existing screening scales. One problem that the authors highlighted is reliance on non-validated instruments (e.g., structural validity based only on exploratory analyses, instruments translated without an additional validation process, or instruments validated in another format). Another problem is that few screening scales establish empirically based cut-off points to identify individuals with a clinically relevant problem (Miner, Raymond, Coleman, \& Swinburne Romine, 2017). Notably, each screening scale is derived from a specific conceptualization (e.g., addictive disorder and obsessive-compulsive disorder), which further emphasizes the current conceptual chaos and hinders the strict comparison of available studies (Karila et al., 2014). An increasing number of scholars agree that sexual addiction, in terms of manifestation and etiology, is equivalent to substance addiction (Potenza, Gola, Voon, Kor, \& Kraus, 2017); however, experts still believe that more research is needed to understand how central features of addiction are expressed in the clinical picture of sex addiction and compulsivity (Kor, Fogel, Reid, \& Potenza, 2013; Kraus, Voon, \& Potenza, 2016). Similarly, the current beta draft of the International Classification of Diseases (ICD-11; World Health Organization, 2018) is now considering the inclusion of compulsive sexual behavior disorder as an impulse control disorder (Kraus et al., 2018), a category intimately linked to other "behavioral addictions," such as gambling or gaming disorder (Grant et al., 2014; Potenza et al., 2017). For this reason, it is reasonable to further validate scales aligned to the current conceptualization of excessive sexual behavior.

Another important issue pertains to the limited diagnostic convergence of existing screening tools. Castro-Calvo, Ballester-Arnal, and Gil-Llario (2015) conducted a study in which three sexual addiction screening scales were administered to 600 Spanish youths. Their results revealed high correlations between scales ( $r$ between .529 and .732 ) but the diagnostic convergence was, at best, $46.3 \%$. One potential explanation for these findings is the lack of systematic validation (in this case in Spanish) of available scales to measure excessive sexual behaviors. Similarly, Wéry et al. (2016) found that $95.8 \%$ of a sample of self-identified sexually addicted patients seeking treatment in an outpatient clinic met the criteria for the diagnosis of sexual addiction according to the SAST, whereas this percentage dropped to $56.9 \%$ and $52.8 \%$ when other diagnostic criteria were applied. Conjointly, these results are in line with the view that traditional screening tools targeting excessive and addictive behaviors frequently produce false-positive cases (Maraz, Király, \& Demetrovics, 2015).

Language limitations are especially relevant, given the scarcity of instruments to assess sexual impulse control in languages other than English (Andreassen, Pallesen, Griffiths, Torsheim, \& Sinha, 2018; Klein, Rettenberger, Boom, \& Briken, 2014; Scanavino et al., 2016). Only 2 of 32 scales cited by Womack, Hook, Ramos, Davis, and
Penberthy (2013) in their review of hypersexual behavior assessment questionnaires had an adapted and validated version in Spanish: the Sexual Compulsivity Scale (SCS; Ballester-Arnal, Gómez-Martínez, Gil-Llario, \& SalmerónSánchez, 2013) and the Internet Sex Screening Test (ISST; Ballester-Arnal, Gil-Llario, Gómez-Martínez, \& Gil-Julià, 2010). Similarly, most contemporary studies recruit and evaluate their participants through the Internet, without considering that the factorial structure, reliability, and scores obtained in the online administration of a questionnaire are not necessarily equivalent to those of the questionnaire's classic paper-and-pencil format (Alfonsson, Maathz, \& Hursti, 2014; Weigold, Weigold, Drakeford, Dykema, \& Smith, 2016). Increasing acknowledgement of this limitation has led to the recent publication of a meta-analysis that examines the psychometric characteristics of the most often used online instruments for clinical assessment (van Ballegooijen, Riper, Cuijpers, van Oppen, \& Smit, 2016). Nevertheless, comparable data are lacking in the field of sex addiction, despite the fact that most recent studies are conducted online (Graham, Walters, Harris, \& Knight, 2016; Jardin et al., 2017; Jerome, Woods, Moskowitz, \& Carrico, 2016; Parsons, Rendina, Ventuneac, Moody, \& Grov, 2016; Štulhofer, Jurin, \& Briken, 2016; Vaillancourt-Morel et al., 2016).

\section{LIMITATIONS OF PREVIOUS STUDIES}

In consideration of these limitations, the main objective of this study was to test the psychometric properties of a Spanish paper-and-pencil and online version of one of the most frequently used scales for the screening of sex addiction: the SAST (Carnes, 1983). This scale was developed to measure excessive sexual behaviors as a behavioral addiction and comprises items recycled from substance abuse disorders to measure symptoms, such as withdrawal, tolerance, or craving. Its use is largely disseminated in clinical and research contexts, and it has been validated in several languages, such as Portuguese (Silveira, Vieira, Palomo, \& Silveira, 2000) and Polish (Gola et al., 2017), but to date, not in Spanish.

Although this instrument and its different versions have been successfully used in research conducted with community samples (Opitz, Tsytsarev, \& Froh, 2009), university students (Giordano, Cashwell, Lankford, King, \& Henson, 2017; Seegers, 2003; Tripodi et al., 2015), at-risk samples (injection drug users, women who are at sexual risk, men who have sex with men, etc.; Storholm, Fisher, Napper, Reynolds, \& Halkitis, 2011), war veterans (Nelson \& Oehlert, 2008), health professionals (Spickard, Swiggart, Manley, \& Dodd, 2002), sex addicts (Blankenship \& Laarser, 2004; Carnes, Hopkins, \& Green, 2014; Weiss, 2004; Wéry et al., 2016), patients with substance-use disorders (Hartman, Ho, Arbour, Janice, \& Lawson, 2012; Stavro et al., 2013), and forensic samples (Hueppelsheuser, Crawford, \& George, 1997; Marshall \& Marshall, 2010; Marshall, Marshall, Moulden, \& Serran, 2008), available psychometric data have provided mixed results (in particular, regarding factorial structure). More precisely, the original validation of the SAST found a one-factor solution that accounted for $50 \%$ of the scale variance (Carnes, 1983) and 
was later replicated through exploratory factor analysis (EFA) in two independent samples (Marshall \& Marshall, 2007; Nelson \& Oehlert, 2008); nevertheless, both replication studies were limited in terms of sample size, sample representativeness, and statistical analysis [in both cases, a classic EFA approach was carried out instead of an EFA based on the polychoric correlation matrix or a confirmatory factor analysis (CFA)]. Furthermore, recent studies have failed to replicate this original factorial structure. For example, in a study performed by the original authors of the SAST in a sample that was similar to that of the initial validation study (783 heterosexual sex addicts; Carnes, Green, \& Carnes, 2010), a principal component analysis of the SAST (again, a classic and unsuitable EFA strategy for dichotomous data analysis) produced a four-factor solution that accounted for $44.08 \%$ of the scale variance. Marshall and Marshall (2010) also obtained a four-factor solution when they assessed the psychometric properties of the SAST in a sample of 231 incarcerated sexual offenders and age-matched non-offenders; however, item distribution and subscale content considerably differed from that obtained by Carnes et al. (2010). Furthermore, a critical review of item clustering revealed inconsistences in this factor solution, such as the inclusion of sexual preoccupation symptoms in both the first and the second factors or the presence of two factors composed of only one item.

Similarly, a recent review about the psychometric properties of the SAST (Montgomery-Graham, 2017) showed that this instrument was appropriate in terms of its internal consistency, but the data on its validity and generalizability were inadequate. Finally, none of the studies performed so far evaluated the temporal consistency of the SAST, the equivalence of the factorial solution in men and women, or the psychometric properties of its online application. Accordingly, the specific goals of the current study were to (a) adapt the SAST from English to Spanish; (b) explore its psychometric properties (factor structure, internal consistency, test-retest stability, and convergent validity); (c) test the goodness of fit of the SAST paper-and-pencil factorial solution during its online administration; and (d) analyze the metric and structural invariance according to gender.

\section{METHODS}

\section{Participants}

The study sample included 2,528 participants distributed into two samples. The first sample (paper-and-pencil group) included 1,585 participants (683 males and 902 females). Their age ranged between 18 and 27 years $(M=20.58$; $S D=24.21$ ). The second sample (online group) included 943 participants (480 males and 463 females) aged between 18 and 40 years $(M=24.21 ; S D=5.49)$. All participants were from Spain. Table 1 shows participants' characteristics for each group. The only differences between the paper-and-pencil and online groups were related to age $(d=0.86)$, sexual orientation $(V=0.31)$, and lifetime sexual intercourse $(V=0.21)$. In these cases, differences between groups reached a medium to large effect size.

\section{Procedure}

Following questionnaire translation guidelines (Harkness, Penell, \& Schoua-Glusberg, 2004), we completed English to Spanish translation of the SAST using group methodology. Four members of the research team with experience in translation and validation of questionnaires, as well as in the study of sexual behaviors, performed independent translations. The various versions were then compared so that the research team could agree on a preliminary version of the questionnaire. This version was then back-translated into English by a bilingual researcher familiar with sexual terminology who had not worked on the previous translation step, and it was compared with the original English scale. After translation discrepancies were resolved, a final version of the SAST was administered to 30 young people to determine whether the items were well understood. After several improvements were made in accordance with the participants' suggestions, the final version was ready (Table A1 in the Appendix).

In the paper-and-pencil group, assessment instruments were administered at information desks located at the main entrance of different higher education centers. Students were asked to voluntarily collaborate with this research. Those who agreed anonymously provided informed consent and the evaluation instruments in paper-and-pencil format. A small percentage of these students were given the opportunity to continue collaborating. Those who accepted were asked to provide an e-mail address and a contact phone number. One year later, 200 of these students (100 males and 100 females) were randomly selected to complete the SAST again. In this group, 50\% completed the SAST in paper-and-pencil format again and $50 \%$ completed it through the ADISEX online platform (http://adiccional sexo.uji.es/). This website offers participants the opportunity to undergo a complete evaluation about sexual addiction and is accessible through any search engine using terms such as "sexual addictions" and/or "sex addiction assessment" (in Spanish). The sample was balanced according to gender and application format (50 males and 50 females completed the paper-and-pencil version of the instrument and the other 50 males and 50 females the online version). The purpose of this test-retest procedure was to cross-validate and verify test-retest stability between the two assessment methods.

In the online study, the SAST and the remaining questionnaires were administered through the ADISEX online platform. To enrich the profile and increase the number of users who went through with the evaluation, we initiated a campaign with the Facebook advertising system (suggested publications) to request collaboration in a research study. The specific objective of the investigation was not mentioned so as not to bias the sampling process. The information provided referred only to the fact that this was a study on sexual behavior. The campaign was focused on young people between 18 and 30 years of age, so that the profiles would correspond to those in the study in the paper-and-pencil format. The data derived from the online platform were processed to avoid duplicitous responses, and only those participants who completed at least $85 \%$ of the assessment tools (considered "motivated participants") were included in the study. 
Table 1. Sample characteristics for each group

\begin{tabular}{|c|c|c|c|}
\hline & Paper-and-pencil group $(n=1,585)$ & Online group $(n=943)$ & \\
\hline & $\%$ or $M(S D)$ & $\%$ or $M(S D)$ & Effect size \\
\hline \multicolumn{4}{|l|}{ Demographics } \\
\hline Sex (male) & 43.1 & 50.9 & \multirow{2}{*}{$V=0.07$} \\
\hline Sex (female) & 56.9 & 49.1 & \\
\hline Age & $20.58(2.17)$ & $24.21(5.49)$ & $d=0.86$ \\
\hline Steady partner (yes) & 52.1 & 57.43 & $V=0.09$ \\
\hline Religious beliefs (atheist) & 55 & 73.1 & \\
\hline Religious beliefs (practicing believer) & 39 & 21.5 & $V=0.18$ \\
\hline Religious beliefs (non-practicing believer) & 6 & 5.4 & \\
\hline Sexual orientation (heterosexual) & 92.2 & 68.4 & \\
\hline Sexual orientation (bisexual) & 3.3 & 15.6 & $V=0.31$ \\
\hline Sexual orientation (homosexual) & 4.6 & 16 & \\
\hline \multicolumn{4}{|l|}{ Sexual behavior } \\
\hline Lifetime sexual intercourse (yes) & 96.6 & 80 & $V=0.21$ \\
\hline Same-sex sexual intercourse (yes) & 14.8 & 29.7 & $V=0.15$ \\
\hline Masturbation (yes) & 87 & 94.4 & $V=0.12$ \\
\hline Mutual masturbation (yes) & 89.9 & 88.9 & $V=0.01$ \\
\hline Oral sex (yes) & 90.6 & 79.4 & $V=0.13$ \\
\hline Vaginal intercourse (yes) & 90.4 & 89.5 & $V=0.01$ \\
\hline Anal intercourse (yes) & 36.4 & 53 & $V=0.15$ \\
\hline
\end{tabular}

Note. SD: standard deviation.

\section{Instruments used in both paper-and-pencil and online groups}

Sexual Addiction Screening Test (SAST; Carnes, 1983). The SAST is a 25-item scale designed to screen for the presence of addictive sexual behaviors and symptoms. It assesses, among other things, sexual preoccupation (e.g., "Do you often find yourself preoccupied with sexual thoughts?"), signs and symptoms of impaired control ("Do you have trouble stopping your sexual behavior when you know it is inappropriate?"), and problems resulting from sexual behavior ("Has your sexual activity interfered with your family life?"). Respondents answer each item on a dichotomous scale (yes/no) and the total score on this instrument can range from 0 to 25 . Internal consistency has been measured with several samples (sex addicts, community members, sex offenders, college students, and veterans), with $\alpha$ values for the total score ranging from .85 to .95 (Womack et al., 2013).

Sexual Compulsivity Scale (SCS; Kalichman et al., 1994), Spanish adaptation (Ballester-Arnal et al., 2013). The SCS is a 10 -item scale that assesses obsessive and intrusive sexual thoughts (e.g., "I feel that my sexual thoughts and feelings are stronger than I am") and out-of-control sexual behaviors ("I sometimes get so horny I could lose control"). Participants rate each item on a 4-point Likert-type scale ranging from 1 (not all like me) to 4 (very much like me). Total scores range from 10 to 40, with higher scores indicating heightened compulsive sexual behavior. The Spanish adaptation of the scale is characterized by a two-factor solution ("interference" and "control") established through EFA in a sample of participants with similar characteristics to those included in this study. In the Spanish validation study, the authors reported an internal consistency of .83 and test-retest reliability (1-month interval) of .72. In this study, internal consistency for the SCS total score and its subscales ranged from .73 to .86 in the paperand-pencil group and from .75 to .87 in the online group.
Hypersexual Behavior Inventory (HBI; Reid, Garos, \& Carpenter, 2011), Spanish adaptation (Ballester-Arnal, Castro-Calvo, Gil-Julià, \& Gil-Llario, in press). The HBI is a 19 -item Likert-type scale $(1=$ never; $5=$ very frequently) designed to measure basic dimensions of hypersexuality. The HBI was originally validated in a male clinical population (Reid et al., 2011). In this sample, the resulting factor structure replicated the theoretical criteria under which HBI was designed. The first factor obtained, labeled "Coping," reflected the use of sex in response to dysphoric mood states; second factor, "Control," showed problems in controlling or reducing sexual thoughts, urges, and behaviors; and the third factor, "Consequences," explored the persistence of sexual fantasies, urges, and behaviors, despite their negative consequences. The authors obtained strong interrelationships among these factors and the reliability for each scale ranged between .89 and .95 . Subsequently, Ballester-Arnal et al. (in press) obtained a similar factorial structure (three first-order factors grouped under a second-order factor) through a CFA in a sample of 2,250 participants between 18 and 40 years old, also demonstrating that the HBI is equally applicable in men and women without changes in its factorial structure (metric and configural invariance). In the Spanish validation study, the authors reported an internal consistency of between .82 and .93 for the total score and the subscales. In this study, reliability for the overall scale and subscales ranged from .82 to .92 for the paper-and-pencil group and from .86 to .94 for the online group.

\section{Instruments used only in online group}

Sexual Sensation Seeking Scale (SSS; Kalichman et al., 1994), Spanish adaptation (Ballester-Arnal, Ruiz-Palomino, Espada-Sánchez, Morell-Mengual, \& Gil-Llario, 2018). The SSS is an 11-item scale rated on a 4-point Likert scale that ranges from 1 (not at all like me) to 4 (very much like me). 
It assesses "the propensity to attain optimal levels of sexual excitement and to engage in novel sexual experiences" (Kalichman et al., 1994, p. 387). Psychometric studies support its use among young people (Gray \& Wilson, 2007) and adolescents (Ballester-Arnal et al., 2018). Internal consistency (Cronbach's $\alpha$ ) for this scale was .82 in its Spanish adaptation. In this study, the same Cronbach's $\alpha$ value was obtained (.82).

Internet Addiction Test (IAT; Young, 1998). The IAT is a 20 -item scale that assesses the extent to which the respondents' use of the Internet is problematic. Participants respond to each question on a 5-point Likert scale that ranges from 1 (rarely) to 5 (always). Summation scores can range from 20 to 100 , with higher values indicating a greater likelihood of Internet addiction. The IAT is one of the most widely used scales to assess Internet addiction (Boysan et al., 2017). In a recent study that used the Spanish translation of the scale, reliability indices were robust $(\alpha=.91$; Castro-Calvo, Ballester-Arnal, Gil-Llario, \& Giménez-García, 2016). In this study, internal consistency for this measure was strong $(\alpha=.91)$.

Internet Sex Screening Test (ISST; Delmonico \& Miller, 2003), Spanish adaptation Ballester-Arnal et al., 2010). The ISST evaluates the degree to which the online sexual behavior of a person is, or is not, problematic. Twenty-five items on a dichotomous scale (true/false) provide a total score (ISSTtotal) ranging from 0 to 25 . In addition, the ISST allows estimation of scores on five subscales: loss of control over online sexual behavior and other pathological indicators (ISST-compulsivity), solitary cybersex (ISST-solitary), social cybersex (ISST-social), economic investment in online sexual activities (ISST-money), and concerns about the severity of cybersex consumption (ISST-severity). Ballester-Arnal et al. (2010) reported good internal consistency $(\alpha=.88)$ and test-retest stability $(r=.82)$ in a sample of college students between 18 and 25 years old. In this study, internal consistency for the ISST-total score $(\alpha=.82)$ and for each subscale (between .63 and .72) was acceptable.

\section{Data analysis}

First, we considered descriptive analyses in relation to sociodemographic and sexual behavior data using the SPSS statistical package (version 24.0). To compare participants' characteristics in both groups (paper-and-pencil and online format), we performed $t$ tests (continuous variables) and $\chi^{2}$ tests (categorical variables). The effect size for these contrasts was computed using $\mathrm{G}^{*}$ Power software (version 3.1); in particular, we estimated Cohen's $d$ and Cramer's $V$ (in $\chi^{2}$ tables, $2 \times k$ is equivalent to Cohen's $W$ index for effect size; Sheskin, 2007).

To determine the factorial structure of the SAST, we first performed an EFA, considering only the participants in the paper-and-pencil group. FACTOR software (version 9.2) was used to perform the EFA (Lorenzo-Seva \& Ferrando, 2013). The main advantage of FACTOR in comparison to other statistical software is the possibility of performing the EFA on the basis of the tetrachoric/polychoric correlation matrix; this option is preferable when modeling dichotomous data (such as in the case of the SAST; Ferrando \& LorenzoSeva, 2017). We used parallel analysis to determine the number of factors to extract (Timmerman \& Lorenzo-Seva, 2011), and they were extracted through robust diagonally weighted least squares (DWLS), applying an oblique rotation (direct oblimin).

Subsequently, a CFA was performed with the participants of the online group. The adjustment of three factorial models was compared and a multigroup CFA was performed to test the hypothesis of measurement invariance (configural, metric, and scalar) according to gender. The software used to perform these analyses was EQS 6.2. The normality violation was corrected using robust methods. The goodness of fit for the different factorial models was analyzed using the following indices: Satorra-Bentler chisquare $\left(\chi^{2}\right)$, relative chi-square $\left(\chi^{2} / d f\right)$, general model significance $(p)$, root mean square error of approximation (RMSEA), and comparative and incremental fit indices (CFI and IFI). An appropriate fit was considered when $\chi^{2}$ was not significant $(p>.05), \chi^{2} / d f$ was between 1 and 2, CFI and IFI were $\geq 0.95$, and RMSEA was $\leq 0.05$ (Bagozzi \& Yi, 2011). According to less restrictive criteria, values between 2 and 3 for $\chi^{2} / d f, \geq 0.90$ for CFI and IFI, and $\leq 0.08$ for RMSEA could also be considered acceptable (Hooper, Coughlan, \& Mullen, 2008).

Finally, the general mean score of the items, subscales, and total score of the SAST were explored, as well as the magnitude of the differences according to the application format. Different reliability indices were calculated; in particular, we employed an R package (userfriendly science) (Peters, 2014) to estimate ordinal Cronbach's $\alpha$ and $\Omega$, Spearman-Brown reliability coefficient (the most appropriate reliability statistic for a two-item scale; Eisinga, Grotenhuis, \& Pelzer, 2013), item-scale, and item-test correlations. We also estimated temporary stability 1 year after the first application. Convergent validity was explored by correlating (Pearson's $r$ ) the SAST total score and its subscales with related measures. Finally, the percentile distribution of the SAST scores was obtained and is included as additional content in the Appendix (Table A2).

\section{Ethics}

The study procedures were carried out in accordance with the Declaration of Helsinki. The Institutional Review Board of the Jaume I University approved the study. Volunteer participants in the research were informed about the study aim and they provided informed consent.

\section{RESULTS}

\section{EFA of the SAST: paper-and-pencil group}

To verify the applicability of the EFA to the SAST, we calculated the Kaiser-Meyer-Olkin index (0.87) and Bartlett's test for sphericity $\left[\chi^{2}(300)=6,171.70, p<.001\right]$. Through analysis of the anti-image correlation matrix, we also verified the adequacy of the 25 SAST items for EFA (all anti-image correlations >.84). After parallel analysis of the polychoric correlation matrix (Garrido, Abad, \& Ponsoda, 2013), we estimated that the appropriate number of factors to be extracted was four (factor eigenvalues $>1.17$ ). The factorial 
Table 2. SAST factorial loadings

\begin{tabular}{|c|c|c|c|c|}
\hline \multirow[b]{2}{*}{ Items } & \multicolumn{4}{|c|}{ Factorial loadings } \\
\hline & Factor 1 & Factor 2 & Factor 3 & Factor 4 \\
\hline \multicolumn{5}{|l|}{ Factor 1: loss of control } \\
\hline 8. Do you ever feel bad about your sexual behavior? & 0.48 & & & \\
\hline 14. Have you made promises to yourself to quit some aspect of your sexual behavior? & 0.78 & & & \\
\hline 15. Have you made efforts to quit a type of sexual activity and failed? & 0.92 & & & \\
\hline 17. Have you attempted to stop some parts of your sexual activity? & 0.90 & & & \\
\hline 21. Have you felt the need to discontinue a certain form of sexual activity? & 0.71 & & & \\
\hline \multicolumn{5}{|l|}{ Factor 2: addiction symptoms } \\
\hline 2. Have you ever subscribed to or regularly purchased sexually explicit magazines? & & 0.49 & & \\
\hline 3. Did your parents have trouble with sexual behavior? & & 0.33 & & \\
\hline 4. Do you often find yourself preoccupied with sexual thoughts? & & 0.35 & & \\
\hline 5. Do you feel that your sexual behavior is not normal? & & 0.52 & & \\
\hline $\begin{array}{l}\text { 6. Does your spouse [or significant other (s)] ever worry or complain about your } \\
\text { sexual behavior? }\end{array}$ & & 0.49 & & \\
\hline $\begin{array}{l}\text { 7. Do you have trouble stopping your sexual behavior when you know it is } \\
\text { inappropriate? }\end{array}$ & & 0.47 & & \\
\hline 13. Are any of your sexual activities against the law? & & 0.43 & & \\
\hline 19. Has sex been a way for you to escape your problems? & & 0.44 & & \\
\hline 23. Have you ever been sexual with minors? & & 0.41 & & \\
\hline 24. Do you feel controlled by your sexual desire? & & 0.72 & & \\
\hline 25. Do you ever think your sexual desire is stronger than you are? & & 0.81 & & \\
\hline \multicolumn{5}{|l|}{ Factor 3: functional impairment } \\
\hline 1. Were you sexually abused as a child or adolescent? & & & 0.32 & \\
\hline 9. Has your sexual behavior ever created problems for you or your family? & & & 0.70 & \\
\hline 10. Have you ever sought help for your sexual behavior that you did not like? & & & 0.24 & \\
\hline 12. Has anyone been hurt emotionally because of your sexual behavior? & & & 0.33 & \\
\hline 18. Have you ever felt degraded by your sexual behavior? & & & 0.47 & \\
\hline 20. When you have sex, do you feel depressed afterward? & & & 0.40 & \\
\hline 22. Has your sexual activity interfered with your family life? & & & 0.92 & \\
\hline \multicolumn{5}{|l|}{ Factor 4: hide } \\
\hline 11. Have you ever worried about people finding out about your sexual activities? & & & & 0.70 \\
\hline 16. Do you have to hide some of your sexual behavior from others? & & & & 0.82 \\
\hline
\end{tabular}

Note. SAST: Sexual Addiction Screening Test.

solution derived from the DWLS factor analysis revealed that this four-factor structure explained $57.39 \%$ of the total variance of the questionnaire. Table 2 includes the standardized factor loadings obtained in the EFA.

The first factor ("loss of control"), which is composed of five items (Items 8, 14, 15, 17, and 21) and has an eigenvalue of 9.43 , explained the highest percentage of the variance $(37.75 \%)$. These items reflect difficulties in controlling and voluntarily resisting impulses, thoughts, and sexual behaviors (e.g., "Have you attempted to stop some parts of your sexual activity?"). With an eigenvalue of 2.04 and $8.17 \%$ of explained variance, the second factor ("addiction symptoms") grouped 11 items (Items 2, 3, 4, 5, $6,7,13,19,23,24$, and 25). This factor comprises several questions with a common denominator: all of them are related to different symptoms included in the sex addiction clinical picture (e.g., "Has sex been a way for you to escape your problems?" or "Do you often find yourself preoccupied with sexual thoughts?"). The seven items that make up the third factor ("functional impairment": Items 1, 9, 10, $12,18,20$, and 22) evaluate the impact of sex addiction on different areas of the patient's life ("Has your sexual activity interfered with your family life?"). This factor has an eigenvalue of 1.68 and an explained variance of $6.74 \%$.
The fourth factor ("hiding") integrates the remaining two items (Items 11 and 16) and has a lower eigenvalue (1.18) and percentage of explained variance $(4.72 \%)$. These items reflect the tendency to conceal one's own sexual behavior ("Do you have to hide some of your sexual behavior from others?").

\section{CFA of the SAST: Online group}

To assess whether the factor structure of the SAST in the paper-and-pencil format was equivalent in its online application, we conducted a CFA. For this purpose, the robust maximum likelihood method was applied (a method that allows one to obtain statistics that correct the normality violation). This method is recommended when analyzing categorical variables (Finney \& DiStefano, 2013). On the basis of the EFA results, two models were compared: the first (M1) replicated the factorial structure derived from the EFA (four correlated first-order factors), and the second (M2) proposed grouping the four first-order factors under a second-order factor that explained the shared variance. To compare the accuracy of these models with the original factor structure, we also tested the goodness of fit of a model that replicated the originally proposed 
Table 3. Goodness-of-fit indices for the CFA and the multigroup CFA

\begin{tabular}{|c|c|c|c|c|c|c|c|}
\hline & $\chi^{2}$ & $d f$ & $p$ & $\chi^{2} / d f$ & RMSEA & CFI & IFI \\
\hline \multicolumn{8}{|l|}{ CFA } \\
\hline Model 1 (M1) & 471.43 & 264 & $<.001$ & 1.78 & 0.02 & 0.92 & 0.93 \\
\hline Model 2 (M2) & 441.59 & 265 & $<.001$ & 1.66 & 0.02 & 0.94 & 0.94 \\
\hline Model 3 (M3) & $1,166.27$ & 274 & $<.001$ & 4.25 & 0.06 & 0.69 & 0.69 \\
\hline \multicolumn{8}{|l|}{ Multigroup CFA } \\
\hline Configural invariance & 812.47 & 528 & $<.001$ & 1.53 & 0.03 & 0.90 & 0.90 \\
\hline Metric invariance & 777.58 & 553 & $<.001$ & 1.40 & 0.03 & 0.92 & 0.92 \\
\hline Scalar invariance & 875.91 & 570 & $<.001$ & 1.53 & 0.03 & 0.92 & 0.92 \\
\hline
\end{tabular}

Note. CFA: confirmatory factor analysis; $\chi^{2}$ : Satorra-Bentler chi-square; $d f$ : degrees of freedom; $p$ : general model significance; $\chi^{2} / d f$ : normed chi-square; RMSEA: root mean square error of approximation; CFI: comparative fit index; IFI: incremental fit index.

one-factor solution (M3). Table 3 shows goodness-of-fit indices for the different models.

As Table 3 shows, the model with the most satisfactory fit indices was the second one (M2). In this model, the $\chi^{2}$ Satorra-Bentler value of significance (corrected $\chi^{2}$ for samples that did not follow the normality assumption) did not exceed the 0.05 value necessary to consider it a satisfactory fit for the model. Nevertheless, it has been shown that this statistic is highly conditioned by sample size (Jöreskog \& Sörbom, 1993; Markland, 2007), which in this study far exceeds the standard required for this type of analysis (Hair, Black, \& Babin, 2010). For this reason, it may be more appropriate to use other indices considered less sensitive to sample size. In this sense, the value of the relative $\chi^{2}\left(\chi^{2} / d f\right)$ was 1.66 , with acceptable fit considered to be values below 3 and perfect fit between 1 and 2. The RMSEA was below the 0.05 value required by the strictest criteria to consider a model parsimonious. Finally, the CFI and the IFI reached a value of 0.94 , which is very close to the cut-off point established to consider it an excellent fit to the model. Both M1 and M2 were superior to the original one-factor solution (M3). The resulting factorial model (M2) is depicted in Figure 1.

To confirm whether the factor structure of the second model (M2) was applicable to men and women, we performed three multigroup CFAs according to gender. In the first, the hypothesis of the factor structure invariance (structural invariance) was tested, whereas in the second, the invariance of the factor loadings (metric invariance) was analyzed. In addition, we tested the hypothesis of the intercepts invariance (scalar invariance). As Table 3 shows, the three models showed an acceptable goodness of fit, although the metric invariance indices were slightly better than the structural and scalar invariance indices. Specifically, the value of the relative $\chi^{2}$ was in all the cases less than 2 (1.53 and 1.40), the RMSEA value was less than 0.05 , and the CFI and IFI indices were equal to or higher than 0.90 . These analyses show that the factor structure of the SAST is equivalent in men and women; in addition, factor loadings and items intercepts did not vary significantly according to gender.

\section{Descriptive data, reliability, and temporal stability of the SAST}

Mean scores of the total sample in the SAST items and factors are reported in Table 4. Regarding internal consistency, ordinal Cronbach's $\alpha$ and $\Omega$ for the majority of the SAST factors and for the total score as well as Spearman-Brown reliability coefficient for factor 4 exceed the criterion established by Hunsley and Mash (2008) to consider the reliability of a scale appropriate. Regarding application format, internal consistency indices were slightly higher for the online version $\left(\alpha_{\text {SAST-Total }}=.96\right.$; $\alpha_{\text {control }}=.95 ; \quad \alpha_{\text {symptoms }}=.91 ; \quad \alpha_{\text {functional-impairment }}=.90$; $\left.\mathrm{S}-\mathrm{B}_{\text {hiding }}=.70\right)$. Internal consistency was also supported by item-scale (between .26 and .88), item-test (.26 and .68), and scale-test correlations (.57 and .89).

Concerning temporal stability, test-retest correlation 1 year after the first paper-and-pencil application was .65 , when the retest was performed in the same format and it was .60 in the online version. The temporal stability of the four factors ranged between .43 and .59 ( $\left.r_{\text {pencil_paper-pencil_paper }}\right)$ and between .22 and .62 ( $\left.r_{\text {pencil_paper_online }}\right)$. In both cases, the temporal stability was lower in the interference factor (which denotes the sensitivity of this scale over time). All correlations were significant at $p<.001$.

\section{Convergent validity of the SAST}

To determine convergent validity, we correlated SAST-total and subscale scores with instruments used to assess the same construct or similar dimensions (Table 5).

As expected, the correlation between SAST and other sexual addiction screening measures, such as the SCS or the HBI was high, positive, and significant (in all cases $r>.22$ and significant at $p<.001$ ). In addition, online participants completed other scales that also showed high, positive, and significant correlations with the SAST-total and subscale scores. Specifically, the correlations between the SAST and the SSS ranged between .16 and .36 and between .23 and .36 with the IAT. Finally, a small to medium relationship was found between the SAST and the ISST, particularly, with the online sexual compulsivity factor (ISST-compulsivity; $r$ between .28 and .45).

\section{DISCUSSION}

The main objective of this study was to adapt and test the psychometric properties of the SAST, one of the most frequently used instruments to screen for sexual addiction. In this sense, the main conclusion derived from this study is 


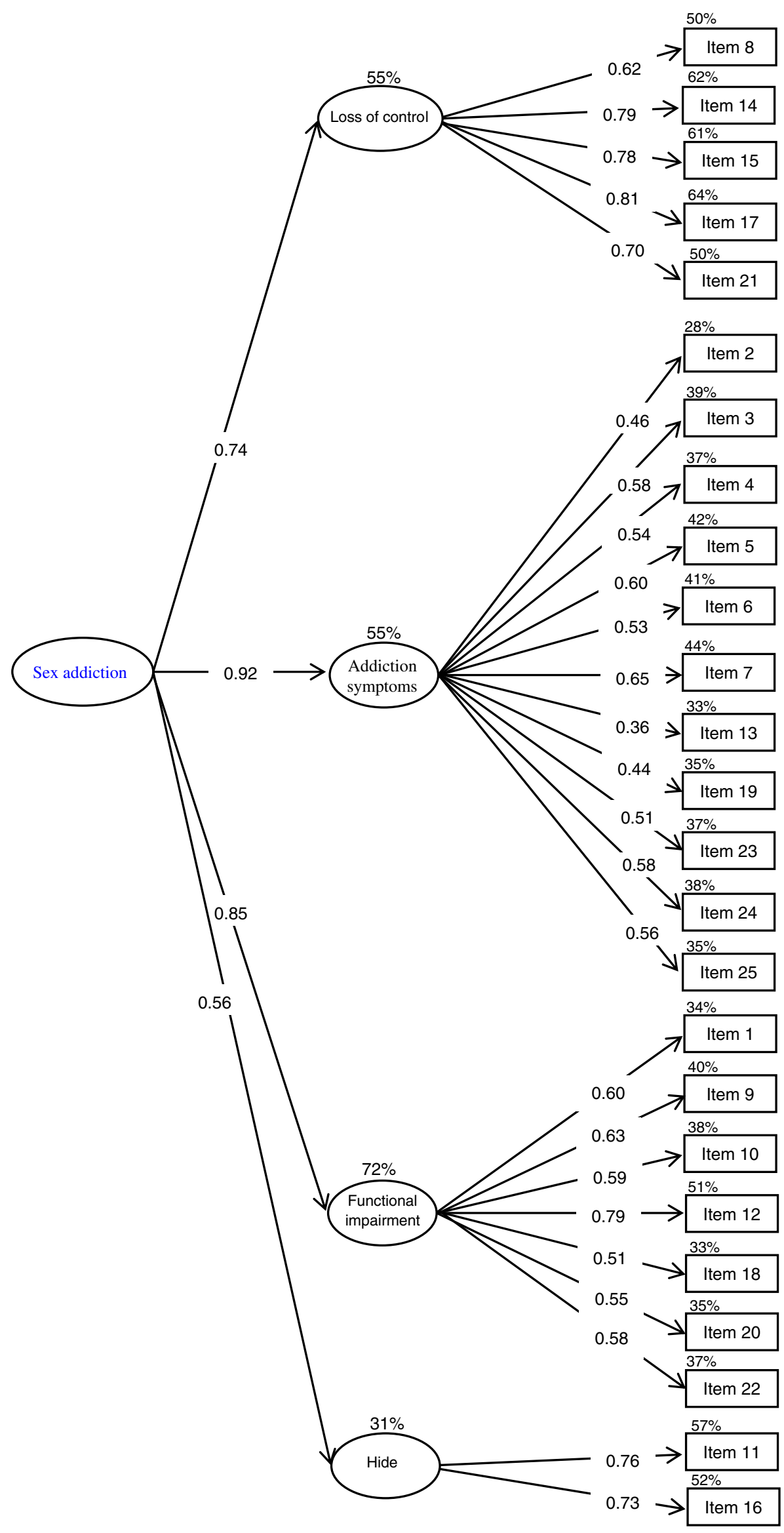

Figure 1. Confirmatory factor analyses for the SAST (M2). $R^{2}$ is expressed as a percentage outside the main endogenous variables boxes. Coefficients are reported in standardized format. All parameters were significant at $p<.001$. Error terms are not included in order to facilitate interpretation 
Castro-Calvo et al.

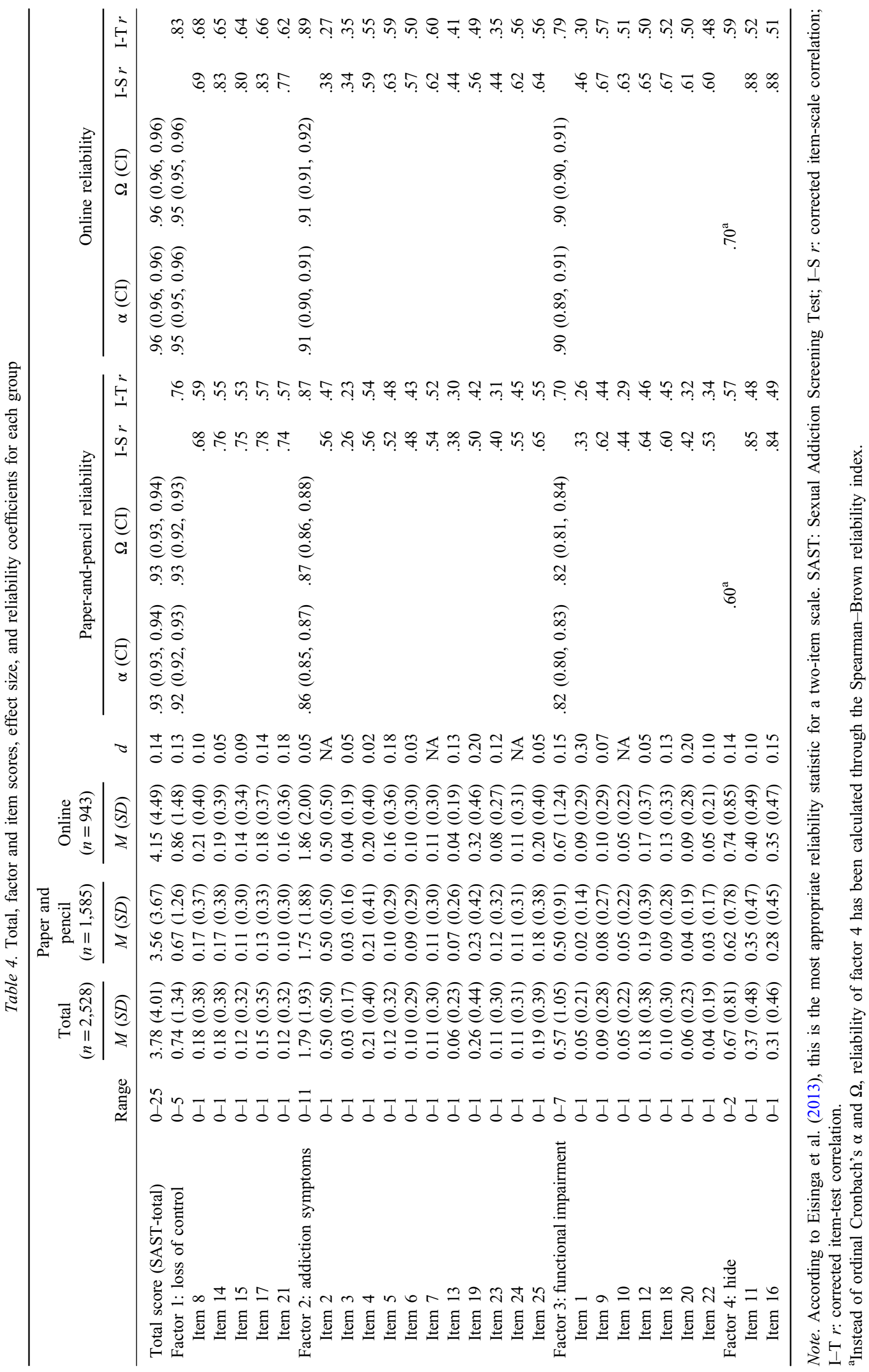


Spanish validation of the SAST

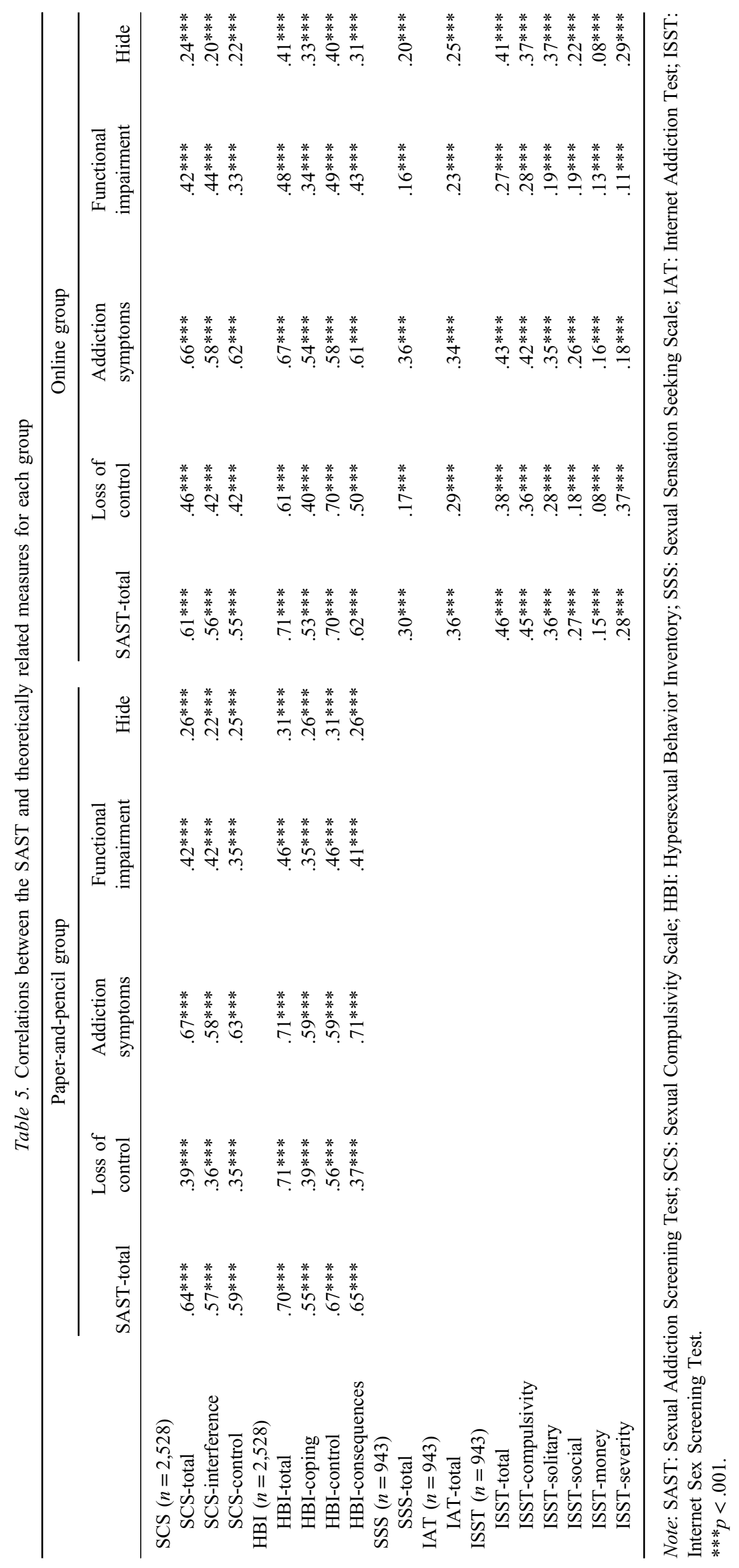


that the SAST is a reliable, valid, and effective tool to assess sex addiction symptoms in both genders. The SAST is also characterized by elevated test-retest reliability, and both versions of the scale (paper and pencil and online) present adequate psychometric properties.

Regarding its factor structure, the 25 items of the SAST load in four subscales that are in turn grouped under a higher order factor, labeled generically as "sex addiction." This higher order factor (which explains between $31 \%$ and $72 \%$ of the variance of the first-order factors) is the psychometric equivalent to the general diagnostic description of the sex addiction condition, while the four subscales represent the main clusters of symptoms encountered.

Among the four factors, "loss of control" is the one with greater explanatory capacity over the entire questionnaire (37.7\% of its variance). Related items assess the capacity to control or voluntarily stop sexual behavior, which is considered the main diagnostic indicator of sex addiction and hypersexuality (Kafka, 2014). Furthermore, it is consistent with one of the main criteria of the ICD-11 in the diagnosis of compulsive sexual behavior disorder: "the person has made numerous unsuccessful efforts to control or significantly reduce repetitive sexual behavior" (Kraus et al., 2018, p. 109).

The second most important factor was "addiction symptoms" ( $8.17 \%$ of the explained variance), so named because it comprises symptoms usually reported by individuals with addictive behaviors. This factor includes questions about the use of sex as a coping strategy, about some of the most frequent symptoms encountered in the condition (e.g., preoccupation and intrusive thoughts), and about the perceived impairing nature of the sexual behavior itself (e.g., perceiving sexual behavior as abnormal), which constitutes some of the most relevant criteria for its diagnosis (Kaplan \& Krueger, 2010). Among them, the use of sex as a coping mechanism has key clinical relevance according to Kafka's formulation of a hypersexuality diagnosis (Kafka, 2010, 2013).

The "functional impairment" factor is related to the tangible negative consequences resulting from excessive sexual behaviors. Functional impairment represents one of the main criteria for the diagnosis of mental disorders in general. Recent papers have emphasized that in the case of behavioral addictions, which mostly relate to common daily life or leisure activities, this criterion should be central and mandatory to endorse the condition (Billieux et al., 2017; Kardefelt-Winther et al., 2017). In particular, the seven items of this factor explore two of the six areas in which sex addiction causes a negative impact according to McBride et al. (2008): family ("Has your sexual behavior ever created problems for you or your family?") and psychological ("When you have sex, do you feel depressed afterward?"). Although it seems too narrow to restrict the screening to two of the six types of negative outcomes, it is also true that it is in the family and personal sphere where the consequences of excessive and problematic sexual behavior tend to be more frequent and serious (Reid et al., 2012; Spenhoff et al., 2013).

Finally, the "Hiding" factor appears especially relevant to sexual addiction, as it is related to symptoms that load on a specific factor. In sexual addictions, it is common for patients to hide their problem from their partner or relatives, which is also one of the main barriers when seeking specialized therapeutic help (Skegg, Nada-Raja, Dickson, \& Paul, 2010; Winters, Christoff, \& Gorzalka, 2010). This is especially relevant in women with sexual addiction, where aspects such as social desirability or peer pressure have been identified as barriers to seeking treatment (Dhuffar \& Griffiths, 2016).

The structural factor shown in this study is not equivalent to those reported in previous psychometric studies, but, to our view, it captures the main components of sexual addiction in a more parsimonious and homogeneous way. Indeed, the four-factor solution obtained by Carnes et al. (2010) blends very different aspects of the clinical picture in the same scale (e.g., Factor 1 includes items regarding loss of control over sexual behavior together with personal distress symptoms), whereas it separates related domains (e.g., functional impairment symptoms are scattered across the first and third factors). Furthermore, it includes a factor ("associated features") that groups together three symptoms that, in our opinion, contribute less to the assessment of sexual addiction (e.g., "Did your parents have trouble with sexual behavior?"). Similarly, Marshall and Marshall (2010) stated that the 25 SAST items could be grouped into four clusters: The first cluster mixes four types of symptoms (concerns about being normal, interference, compulsivity, and sexual preoccupations), the content of the first and second clusters (once again, sexual preoccupations) is redundant, and the third and fourth clusters comprise a single item. On the other hand, our proposal of a factorial model in which a second-order factor explains the shared variance between the first-order scales is compatible with the original one-factor solution proposed by Carnes (1989) and replicated later in two independent samples (Marshall \& Marshall, 2007; Nelson \& Oehlert, 2008). Furthermore, it supports the classic conception of sex addiction as a unitary construct (Graham et al., 2016) and the suitability of using a global SAST score as an indicator of general severity.

Regarding psychometric properties, this study demonstrates that the SAST is a reliable and valid screen for sexual addiction. Cronbach's $\alpha$ and $\Omega$ of the total score was .93 in the paper-and-pencil format and .96 in the online version. These values are higher to those obtained in previous validation studies (Montgomery-Graham, 2017). In addition, the SAST scores - especially the total score - were stable 1 year after the initial administration ( $r$ between .60 and .65), regardless of the format in which the retest was administered. To date, no study has explored the temporal stability of this scale (Montgomery-Graham, 2017) much less for such a long time span. The weaker temporal stability was obtained for the functional impairment construct, which is one of the most sensitive symptoms in the episodic evolution that characterizes the clinical course of this disorder (Reid et al., 2012). Finally, correlations with the total score of other screening instruments, such as the SCS ( $r=.64$ and .61 in the paper-and-pencil and online group, respectively) or the HBI ( $r$ of .70 and .61), as well as other related variables, such as sexual sensation seeking $(r=.30)$, Internet addiction $(r=.36)$, and cybersex addiction $(r=.46)$, support the validity of the SAST. 
In the process of validating the Spanish SAST, we paid special attention to three aspects. The first was its applicability in men and women. In this sense, this study confirms that the factor structure of the SAST is equivalent in men and women (structural, metric, and scalar invariance), allowing, for example, gender comparison on this scale in future studies. The second aspect was the administration format. Most research on sex addiction is conducted completely or partially on the Internet, implying the online administration of scales originally designed for paper-andpencil application. In this sense, this study allowed us to affirm that both the factor structure and the psychometric properties of the SAST are equivalent regardless of whether it is applied in classic format or through the Internet. The final aspect that we paid special attention to was data analysis in order to tackle the methodological shortcomings of previous studies. As far as we know, this is the first study in which the EFA of the SAST was carried out on the basis of the polychoric correlation matrix (mandatory when modeling dichotomous data). Only one previous study conducted a CFA of the SAST (Marshall \& Marshall, 2010); however, the limited sample size to carry out this analysis (151 participants), together with its heterogeneity (sexual offenders and community members) and problems during data reporting (e.g., authors did not report goodnessof-fit indicators for the CFA), leads to questions about the reliability of the results. For this reason, we consider that a CFA performed with methodological guaranties to be an important contribution to existing knowledge regarding the factorial structure of the SAST.

\section{Limitations and future directions}

The main limitation of the current work is related to item content and distribution among the four factors. In our opinion, some of the items originally included in the SAST (e.g., "Were you sexually abused as a child or adolescent?") do not have real clinical utility in the assessment and diagnosis of sexual addiction. However, after considering the possibility of creating a new version of the SAST without these items, we decided to respect the scale's integrity in order to facilitate the comparison of its results with those obtained in previous studies. Moreover, in some cases, the item content does not perfectly match the subscale to which it is allocated (e.g., Item 7 better fits Factor 1 than Factor 2) or the factor loading is low (item 10). To tackle these limitations, we considered and tested alternative factorial solutions, obtaining in all cases worse psychometric results, which justified the decision to maintain the proposed factorial solution. Finally, the fourth factor ("hide") comprises two items, whereas guidelines usually recommend the inclusion of at least three items per scale for specifying a latent factor (Raubenheimer, 2004). Even so, we decided to go through with our proposal of prioritizing the clinical importance of the inclusion of a scale to reflect the symptoms. In addition, we have adapted our statistical approach (e.g., reliability estimation through Spearman-Brown index) to minimize the potential issues related to the use of this two-item scale (Eisinga et al., 2013)

Regarding the nature of the sample used for the validation of the SAST, since the study did not consider the participation of men and women with clinical problems of sexual addiction, it is not possible to determine with true certainty the diagnostic validity of the SAST. This is one of the aspects to be investigated in order to assure the validity of SAST in identifying patients with clinical problems of sex addiction, as well as to obtain cut-off points that allow their detection through epidemiological studies in large samples of the general population (Miner et al., 2017). In addition, only higher education students participated in the paper-and-pencil group, a limitation that was subsequently addressed through the inclusion of a larger age range in the online sample. This is the first study to test the psychometric properties of the Spanish SAST, which is an important step forward in expanding the limited supply of scales used to evaluate sexual addiction in languages other than English.

Funding sources: This research was supported by grant P1.1B2012-49 and P1.1B2015-82 of the University Jaume I of Castellón, APOSTD/2017/005 of the County Council Department of Education, Culture and Sports of the Valencian Community, and grant PSI2011-27992/11 I 384 of the Ministry of Science and Innovation (Spain).

Authors' contribution: RB-A and MDG-L contributed to study design, obtaining funding, and study supervision. RB-A, MDG-L, JC-C, BG-J, and JB participated in recruiting participants, collecting data, analysis/interpretation of data, and/or writing of the paper.

Conflict of interest: The authors declare no conflict of interest.

\section{REFERENCES}

Alfonsson, S., Maathz, P., \& Hursti, T. (2014). Interformat reliability of digital psychiatric self-report questionnaires: A systematic review. Journal of Medical Internet Research, 16(12), e268. doi:10.2196/jmir.3395

Allen, A., Kannis-Dymand, L., \& Katsikitis, M. (2017). Problematic Internet pornography use: The role of craving, desire thinking, and metacognition. Addictive Behaviors, 70, 65-71. doi:10.1016/j.addbeh.2017.02.001

Andreassen, C. S., Pallesen, S., Griffiths, M. D., Torsheim, T., \& Sinha, R. (2018). The development and validation of the Bergen-Yale Sex Addiction Scale with a large national sample. Frontiers in Psychology, 9, 144. doi:10.3389/fpsyg.2018.00144

Bagozzi, R. P., \& Yi, Y. (2011). Specification, evaluation, and interpretation of structural equation models. Journal of the Academy of Marketing Science, 40(1), 8-34. doi:10.1007/ s11747-011-0278-x

Ballester-Arnal, R., Castro-Calvo, J., Gil-Julià, B., \& Gil-Llario, M. D. (in press). A validation study of the Spanish version of the Hypersexual Behavior Inventory (HBI): Pencil and paper versus online administration. Journal of Sex and Marital Therapy.

Ballester-Arnal, R., Gil-Llario, M. D., Gómez-Martínez, S., \& Gil-Julià, B. (2010). Psychometric properties of an instrument for assessing cyber-sex addiction. Psicothema, 22(4), 1048-1053. 
Ballester-Arnal, R., Gómez-Martínez, S., Gil-Llario, M. D., \& Salmerón-Sánchez, P. (2013). Sexual Compulsivity Scale: Adaptation and validation in the Spanish population. Journal of Sex \& Marital Therapy, 39(6), 526-540. doi:10.1080/ 0092623X.2012.665816

Ballester-Arnal, R., Ruiz-Palomino, E., Espada-Sánchez, J. P., Morell-Mengual, V., \& Gil-Llario, M. D. (2018). Psychometric properties and validation of the Sexual Sensation Seeking Scale in Spanish adolescents: Brief screening method for use in research and clinical practice. Personality and Individual Differences, 122, 47-54. doi:10.1016/ J.PAID.2017.10.006

Billieux, J., King, D. L., Higuchi, S., Achab, S., Bowden-Jones, H., Hao, W., Long, J., Lee, H. K., Potenza, M. N., Saunders, J. B., \& Poznyak, V. (2017). Functional impairment matters in the screening and diagnosis of gaming disorder. Journal of Behavioral Addictions, 6(3), 285-289. doi:10.1556/2006.6.2017.036

Blankenship, R., \& Laarser, M. (2004). Sexual addiction and ADHD: Is there a connection? Sexual Addiction \& Compulsivity, 11(1-2), 7-20. doi:10.1080/10720160490458184

Boysan, M., Kuss, D. J., Barut, Y., Ayköse, N., Güleç, M., \& Özdemir, O. (2017). Psychometric properties of the Turkish version of the Internet Addiction Test (IAT). Addictive Behaviors, 64, 247-252. doi:10.1016/j.addbeh.2015.09.002

Carnes, P. J. (1983). Out of the shadows: Understanding sexual addiction. Minneapolis, MN: CompCare Publishers.

Carnes, P. J. (1989). Contrary to love: Helping the sexual addict. Minneapolis, MN: CompCare Publishers.

Carnes, P. J., Green, B., \& Carnes, S. (2010). The same yet different: Refocusing the Sexual Addiction Screening Test (SAST) to reflect orientation and gender. Sexual Addiction \& Compulsivity, 17(1), 7-30. doi:10.1080/10720161003604087

Carnes, P. J., Hopkins, T. A., \& Green, B. A. (2014). Clinical relevance of the proposed sexual addiction diagnostic criteria. Journal of Addiction Medicine, 8(6), 450-461. doi:10.1097/ ADM.0000000000000080

Castro-Calvo, J., Ballester-Arnal, R., \& Gil-Llario, M. D. (2015). Compulsividad sexual: Convergencia y prevalencia entre medidas [Sexual compulsitivy: Prevalence and diagnostic convergence between assessment instruments]. Agora de Salut, 2, 205-213. doi:10.6035/AgoraSalut.2015.2.20

Castro-Calvo, J., Ballester-Arnal, R., Gil-Llario, M. D., \& GiménezGarcía, C. (2016). Common etiological pathways between toxic substance use, Internet and cybersex addiction: The role of expectancies and antisocial deviance proneness. Computers in Human Behavior, 63, 383-391. doi:10.1016/j.chb. 2016.05.066

Delmonico, D., \& Miller, J. (2003). The Internet Sex Screening Test: A comparison of sexual compulsives versus non-sexual compulsives. Sexual and Relationship Therapy, 18, 261-276. doi:10.1080/1468199031000153900

Dhuffar, M. K., \& Griffiths, M. D. (2016). Barriers to female sex addiction treatment in the UK. Journal of Behavioral Addictions, 5(4), 562-567. doi:10.1556/2006.5.2016.072

Eisinga, R., Te Grotenhuis, M., \& Pelzer, B. (2013). The reliability of a two-item scale: Pearson, Cronbach, or Spearman-Brown? International Journal of Public Health, 58(4), 637-642. doi:10.1007/s00038-012-0416-3

Ferrando, P. J., \& Lorenzo-Seva, U. (2017). Program FACTOR at 10: Origins, development and future directions. Psicothema, 29(2), 236-240. doi:10.7334/psicothema2016.304
Finney, S. J., \& DiStefano, C. (2013). Nonnormal and categorical data in structural equation modeling. In G. R. Hancock, \& R. O. Mueller (Eds.), Structural equation modeling: A second course (2nd ed., p. 439-492). Charlotte, NC: Information Age Publishing.

Garrido, L. E., Abad, F. J., \& Ponsoda, V. (2013). A new look at Horn's parallel analysis with ordinal variables. Psychological Methods, 18(4), 454-474. doi:10.1037/a0030005

Giordano, A. L., Cashwell, C. S., Lankford, C., King, K., \& Henson, R. K. (2017). Collegiate sexual addiction: Exploring religious coping and attachment. Journal of Counseling \& Development, 95(2), 135-144. doi:10.1002/jcad.12126

Gola, M., Skorko, M., Kowalewska, E., Kołodziej, A., Sikora, M., Wodyk, M., Wodyk, Z., \& Dobrowolski, P. (2017). Polish adaptation of Sexual Addiction Screening Test - Revised. Psychiatria Polska, 51(1), 95-115. doi:10.12740/PP/OnlineFirst/61414

Graham, F. J., Walters, G. D., Harris, D. A., \& Knight, R. A. (2016). Is hypersexuality dimensional or categorical? Evidence from male and female college samples. The Journal of Sex Research, 53(2), 224-238. doi:10.1080/00224499.2014.1003524

Grant, J. E., Atmaca, M., Fineberg, N. A., Fontenelle, L. F., Matsunaga, H., Janardhan Reddy, Y. C., Simpson, H. B., Thomsen, P. H., van den Heuvel, O. A., Veale, D., Woods, D. W., \& Stein, D. J. (2014). Impulse control disorders and behavioural addictions in the ICD-11. World Psychiatry, 13(2), 125-127. doi:10.1002/wps.20115

Gray, J. M., \& Wilson, M. A. (2007). A detailed analysis of the reliability and validity of the Sensation Seeking Scale in a UK sample. Personality and Individual Differences, 42(4), 641-651. doi:10.1016/j.paid.2006.08.019

Hair, J. F., Black, W. C., \& Babin, B. J. (2010). Multivariate data analysis: A global perspective. Boston, MA: Pearson.

Harkness, J., Penell, B. E., \& Schoua-Glusberg, A. (2004). Survey questionnaire translation and assessment. In S. Presser, J. M. Rothgeb, M. P. Couper, J. T. Lessler, E. Martin, J. Martin, \& E. Singer (Eds.), Methods for testing and evaluating survey questionnaires (pp. 453-473). Hoboken, NJ: Wiley.

Hartman, L. I., Ho, V., Arbour, S., Janice, M., \& Lawson, P. (2012). Sexual addiction and substance addiction: Comparing sexual addiction treatment outcomes among clients with and without comorbid substance use disorders. Sexual Addiction \& Compulsivity, 19(4), 284-309. doi:10.1080/10720162.2012.735515

Hook, J. N., Hook, J. P., Davis, D. E., Worthington, E. L., \& Penberthy, J. K. (2010). Measuring sexual addiction and compulsivity: A critical review of instruments. Journal of Sex \& Marital Therapy, 36, 227-260. doi:10.1080/0092 6231003719673

Hooper, D., Coughlan, J., \& Mullen, M. R. (2008). Structural equation modeling: Guidelines for determining model fit. Electronic Journal on Business Research Methods, 6(1), 53-60.

Hueppelsheuser, M., Crawford, P., \& George, D. (1997). The link between incest abuse and sexual addiction. Sexual Addiction \& Compulsivity, 4(4), 335-355. doi:10.1080/10720169708404237

Hunsley, J., \& Mash, E. J. (2008). A guide to assessments that work. Oxford, UK: Oxford University Press.

Jardin, C., Sharp, C., Garey, L., Vanwoerden, S., Crist, N., Elhai, J. D., \& Zvolensky, M. J. (2017). Compelled to risk: Does sexual compulsivity explain the connection between borderline personality disorder features and number of sexual partners? Journal of Personality Disorders, 31, 1-15. doi:10.1521/ pedi_2017_31_277 
Jerome, R. C., Woods, W. J., Moskowitz, J. T., \& Carrico, A. W. (2016). The psychological context of sexual compulsivity among men who have sex with men. AIDS and Behavior, 20(2), 273-280. doi:10.1007/s10461-015-1083-1

Jöreskog, K., \& Sörbom, D. (1993). LISREL 8: Structural equation modeling with the SIMPLIS command language. Chicago, IL: Scientific Software International Inc.

Kafka, M. P. (2010). Hypersexual disorder: A proposed diagnosis for DSM-V. Archives of Sexual Behavior, 39(2), 377-400. doi:10.1007/s10508-009-9574-7

Kafka, M. P. (2013). The development and evolution of the criteria for a newly proposed diagnosis for DSM-5: Hypersexual disorder. Sexual Addiction \& Compulsivity, 20(1-2), 19-26. doi:10.1080/10720162.2013.768127

Kafka, M. P. (2014). What happened to hypersexual disorder? Archives of Sexual Behavior, 43(7), 1259-1261. doi:10.1007/ s10508-014-0326-y

Kalichman, S. C., Johnson, J. R., Adair, V., Rompa, D., Multhauf, K., \& Kelly, J. A. (1994). Sexual sensation seeking: Scale development and predicting AIDS-risk behavior among homosexually active men. Journal of Personality Assessment, 62(3), 385-397. doi:10.1207/s15327752jpa6203_1

Kaplan, H. S., \& Krueger, R. B. (2010). Diagnosis, assessment, and treatment of hypersexuality. Journal of Sex Research, 47(2), 181-198. doi:10.1080/00224491003592863

Kardefelt-Winther, D., Heeren, A., Schimmenti, A., van Rooij, A., Maurage, P., Carras, M., Edman, J., Blaszczynski, A., Khazaal, Y., \& Billieux, J. (2017). How can we conceptualize behavioural addiction without pathologizing common behaviours? Addiction, 112(10), 1709-1715. doi:10.1111/add.13763

Karila, L., Wéry, A., Weinstein, A., Cottencin, O., Petit, A., Reynaud, M., \& Billieux, J. (2014). Sexual addiction or hypersexual disorder: Different terms for the same problem? A review of the literature. Current Pharmaceutical Design, 20(25), 4012-4020.

King, D. L., Herd, M. C. E., \& Delfabbro, P. H. (2017). Tolerance in Internet gaming disorder: A need for increasing gaming time or something else? Journal of Behavioral Addictions, 6(4), 525-533. doi:10.1556/2006.6.2017.072

Klein, V., Rettenberger, M., Boom, K.-D., \& Briken, P. (2014). Eine Validierungsstudie der deutschen Version des Hypersexual Behavior Inventory (HBI) [A validation study of the German version of the Hypersexual Behavior Inventory (HBI)]. Psychotherapie Psychosomatik Medizinische Psychologie, 64(3-4), 136-140. doi:10.1055/s-0033-1357133

Kor, A., Fogel, Y., Reid, R. C., \& Potenza, M. N. (2013). Should hypersexual disorder be classified as an addiction? Sexual Addiction \& Compulsivity, 20(1-2), 27-47. doi:10.1080/10720162. 2013.768132

Kraus, S. W., Krueger, R. B., Briken, P., First, M. B., Stein, D. J., Kaplan, M. S., Voon, V., Abdo, C. H. N., Grant, J. E., Atalla, E., \& Reed, G. M. (2018). Compulsive sexual behaviour disorder in the compulsive sexual behaviour disorder in the ICD-11. World Psychiatry, 17(1), 109-110. doi:10.1002/ wps. 20499

Kraus, S. W., Voon, V., \& Potenza, M. N. (2016). Should compulsive sexual behavior be considered an addiction? Addiction, 111(12), 2097-2106. doi:10.1111/add.13297

Lorenzo-Seva, U., \& Ferrando, P. J. (2013). FACTOR 9.2: A comprehensive program for fitting exploratory and semiconfirmatory factor analysis and IRT models. Applied Psychological Measurement, 37(6), 497-498. doi:10.1177/ 0146621613487794

Maraz, A., Király, O., \& Demetrovics, Z. (2015). Commentary on: Are we overpathologizing everyday life? A tenable blueprint for behavioral addiction research. Journal of Behavioral Addictions, 4(3), 151-154. doi:10.1556/2006.4.2015.026

Markland, D. (2007). The golden rule is that there are no golden rules: A commentary on Paul Barrett's recommendations for reporting model fit in structural equation modelling. Personality and Individual Differences, 42(5), 851-858. doi:10.1016/j. paid.2006.09.023

Marshall, L. E., \& Marshall, W. L. (2007). Sexual addiction in incarcerated sexual offenders. Sexual Addiction \& Compulsivity, 13(4), 377-390. doi:10.1080/10720160601011281

Marshall, L. E., \& Marshall, W. L. (2010). The factorial structure of the Sexual Addiction Screening Test in sexual offenders and socio-economically matched community non-offenders. Sexual Addiction \& Compulsivity, 17(3), 210-218. doi:10.1080/ 10720162.2010.502073

Marshall, L. E., Marshall, W. L., Moulden, H. M., \& Serran, G. A. (2008). The prevalence of sexual addiction in incarcerated sexual offenders and matched community nonoffenders. Sexual Addiction \& Compulsivity, 15, 271-283. doi:10.1080/ 10720160802516328

McBride, K. R., Reece, M., \& Sanders, S. A. (2008). Predicting negative outcomes of sexuality using the Compulsive Sexual Behavior Inventory. International Journal of Sexual Health, 19(4), 51-62. doi:10.1300/J514v19n04_06

Miner, M. H., Raymond, N., Coleman, E., \& Swinburne Romine, R. (2017). Investigating clinically and scientifically useful cut points on the Compulsive Sexual Behavior Inventory. The Journal of Sexual Medicine, 14(5), 715-720. doi:10.1016/j. jsxm.2017.03.255

Montgomery-Graham, S. (2017). Conceptualization and assessment of hypersexual disorder: A systematic review of the literature. Sexual Medicine Reviews, 5(2), 146-162. doi:10.1016/ j.sxmr.2016.11.001

Nelson, K. G., \& Oehlert, M. E. (2008). Psychometric exploration of the Sexual Addiction Screening Test in veterans. Sexual Addiction \& Compulsivity, 15(1), 39-58. doi:10.1080/ 10720160701876609

Odlaug, B. L., \& Grant, J. E. (2010). Impulse-control disorders in a college sample: Results from the self-administered Minnesota Impulse Disorders Interview (MIDI). Primary Care Companion to the Journal of Clinical Psychiatry, 12(2), 4-11. doi:10.4088/PCC.09m00842whi

Odlaug, B. L., Lust, K., Schreiber, L. R. N., Christenson, G., Derbyshire, K., Harvanko, A., Golden, D., \& Grant, J. E. (2013). Compulsive sexual behavior in young adults. Annals of Clinical Psychiatry, 25(3), 193-200.

Opitz, D. M., Tsytsarev, S. V., \& Froh, J. (2009). Women's sexual addiction and family dynamics, depression and substance abuse women's sexual addiction and family. Sexual Addiction \& Compulsivity, 16(4), 324-340. doi:10.1080/ 10720160903375749

Parsons, J. T., Rendina, H. J., Ventuneac, A., Moody, R. L., \& Grov, C. (2016). Hypersexual, sexually compulsive, or just highly sexually active? Investigating three distinct groups of gay and bisexual men and their profiles of HIV-related sexual 
risk. AIDS and Behavior, 20(2), 262-272. doi:10.1007/ s10461-015-1029-7

Peters, G.-J. Y. (2014). The alpha and the omega of scale reliability and validity: Why and how to abandon Cronbach's alpha and the route towards more comprehensive assessment of scale quality. European Health Psychologist, 16(2), 56-69.

Potenza, M. N., Gola, M., Voon, V., Kor, A., \& Kraus, S. W. (2017). Is excessive sexual behaviour an addictive disorder? The Lancet. Psychiatry, 4(9), 663-664. doi:10.1016/S22150366(17)30316-4

Raubenheimer, J. (2004). An item selection procedure to maximise scale realiabity and validity. Journal of Industrial Psychology, 30(4), 59-64. doi:10.4102/sajip.v30i4.168

Reid, R. C., Carpenter, B. N., Hook, J. N., Garos, S., Manning, J. C., Gilliland, R., Cooper, E. B., McKittrick, H., Davtian, M., \& Fong, T. (2012). Report of findings in a DSM-5 field trial for hypersexual disorder. The Journal of Sexual Medicine, 9(11), 2868-2877. doi:10.1111/j.1743-6109.2012.02936.x

Reid, R. C., Garos, S., \& Carpenter, B. N. (2011). Reliability, validity, and psychometric development of the Hypersexual Behavior Inventory in an outpatient sample of men. Sexual Addiction \& Compulsivity, 18(1), 30-51. doi:10.1080/10720162. 2011.555709

Reid, R. C., Harper, J. M., \& Anderson, E. H. (2009). Coping strategies used by hypersexual patients to defend against the painful effects of shame. Clinical Psychology \& Psychotherapy, 16(2), 125-138. doi:10.1002/cpp.609

Rettenberger, M., Klein, V., \& Briken, P. (2015). The relationship between hypersexual behavior, sexual excitation, sexual inhibition, and personality traits. Archives of Sexual Behavior, 45(1), 219-233. doi:10.1007/s10508-014-0399-7

Rosenberg, K. P., Carnes, P. J., \& O'Connor, S. (2014). Evaluation and treatment of sex addiction. Journal of Sex \& Marital Therapy, 40(2), 77-91. doi:10.1080/0092623X.2012.701268

Scanavino, M. de T., Ventuneac, A., Rendina, H. J., Abdo, C. H. N., Tavares, H., Amaral, M. L., Messina, B., Reis, S. C., Martins, J. P., Gordon, M. C., Vieira, J. C., \& Parsons, J. T. (2016). Sexual Compulsivity Scale, Compulsive Sexual Behavior Inventory, and Hypersexual Disorder Screening Inventory: Translation, adaptation, and validation for use in Brazil. Archives of Sexual Behavior, 45(1), 207-217. doi:10.1007/s10508-014-0356-5

Seegers, J. A. (2003). The prevalence of sexual addiction symptoms on the college campus. Sexual Addiction \& Compulsivity, 10(4), 247-258. doi:10.1080/10720160390268942

Sheskin, D. (2007). Handbook of parametric and nonparametric statistical procedures. London, UK: Chapman \& Hall/CRC Press.

Silveira, D. X., Vieira, A. C., Palomo, V., \& Silveira, E. D. (2000). Criteria validity and reliability of the Brazilian version of a Sexual Addiction Screening Scale. Revista Brasileira de Psiquiatria, 22(1), 4-10. doi:10.1590/S1516-44462000000100003

Skegg, K., Nada-Raja, S., Dickson, N., \& Paul, C. (2010). Perceived out of control sexual behavior in a cohort of young adults from the Dunedin Multidisciplinary Health and Development Study. Archives of Sexual Behavior, 39(4), 968-978. doi:10.1007/s10508-009-9504-8

Spenhoff, M., Kruger, T. H. C., Hartmann, U., \& Kobs, J. (2013). Hypersexual behavior in an online sample of males: Associations with personal distress and functional impairment. The Journal of Sexual Medicine, 10(12), 2996-3005. doi:10.1111/jsm.12160
Spickard, A., Swiggart, W. H., Manley, G., \& Dodd, D. (2002). A continuing education course for physicians who cross sexual boundaries. Sexual Addiction \& Compulsivity, 9(1), 33-42. doi:10.1080/107201602317346629

Starcevic, V. (2016). Tolerance and withdrawal symptoms may not be helpful to enhance understanding of behavioural addictions. Addiction, 111(7), 1307-1308. doi:10.1111/add.13381

Stavro, K., Rizkallah, E., Dinh-williams, L., Stavro, K., Rizkallah, E., \& Dinh-Williams, L. (2013). Hypersexuality among a substance use disorder population hypersexuality among a substance use disorder population. Sexual Addiction \& Compulsivity, 20(3), 210-216. doi:10.1080/10720162.2013.787379

Storholm, E. D., Fisher, D. G., Napper, L. E., Reynolds, L., \& Halkitis, P. N. (2011). A psychometric analysis of the Compulsive Sexual Behavior Inventory. Sexual Addiction \& Compulsivity, 18(2), 86-103. doi:10.1080/10720162.2011. 584057

Štulhofer, A., Jurin, T., \& Briken, P. (2016). Is high sexual desire a facet of male hypersexuality? Results from an online study. Journal of Sex \& Marital Therapy, 42(8), 665-680. doi:10.1080/ 0092623X.2015.1113585

Timmerman, M. E., \& Lorenzo-Seva, U. (2011). Dimensionality assessment of ordered polytomous items with parallel analysis. Psychological Methods, 16(2), 209-220. doi:10.1037/a0023353

Tripodi, F., Eleuteri, S., Giuliani, M., Rossi, R., Livi, S., Petruccelli, I., Petruccellie, F., Daneback, K., \& Simonelli, C. (2015). Unusual online sexual interests in heterosexual Swedish and Italian university students. Sexologies, 24(4), e84-e93. doi:10.1016/j.sexol.2015.03.003

Vaillancourt-Morel, M.-P., Dugal, C., Poirier Stewart, R., Godbout, N., Sabourin, S., Lussier, Y., \& Briere, J. (2016). Extradyadic sexual involvement and sexual compulsivity in male and female sexual abuse survivors. The Journal of Sex Research, 53(4-5), 614-625. doi:10.1080/00224499.2015.1061633

van Ballegooijen, W., Riper, H., Cuijpers, P., van Oppen, P., \& Smit, J. H. (2016). Validation of online psychometric instruments for common mental health disorders: A systematic review. BMC Psychiatry, 16(1), 45. doi:10.1186/s12888-0160735-7

Walters, G. D., Knight, R. A., \& Långström, N. (2011). Is hypersexuality dimensional? Evidence for the DSM-5 from general population and clinical samples. Archives of Sexual Behavior, 40(6), 1309-1321. doi:10.1007/s10508-010-9719-8

Weigold, A., Weigold, I. K., Drakeford, N. M., Dykema, S. A., \& Smith, C. A. (2016). Equivalence of paper-and-pencil and computerized self-report surveys in older adults. Computers in Human Behavior, 54, 407-413. doi:10.1016/j.chb.2015.08.033

Weiss, D. (2004). The prevalence of depression in male sex addicts residing in the United States. Sexual Addiction \& Compulsivity, 11(1-2), 57-69. doi:10.1080/10720160490458247

Wéry, A., \& Billieux, J. (2017). Problematic cybersex: Conceptualization, assessment, and treatment. Addictive Behaviors, 64, 238-246. doi:10.1016/j.addbeh.2015.11.007

Wéry, A., Vogelaere, K., Challet-Bouju, G., Poudat, F.-X., Caillon, J., Lever, D., Billieux, J., \& Grall-Bronnec, M. (2016). Characteristics of self-identified sexual addicts in a behavioral addiction outpatient clinic. Journal of Behavioral Addictions, 5(4), 623-630. doi:10.1556/2006.5.2016.071

Winters, J., Christoff, K., \& Gorzalka, B. B. (2010). Dysregulated sexuality and high sexual desire: Distinct constructs? Archives 
of Sexual Behavior, 39(5), 1029-1043. doi:10.1007/s10508009-9591-6

Womack, S., Hook, J., Ramos, M., Davis, D. E., \& Penberthy, J. K. (2013). Measuring hypersexual behavior. Sexual Addiction \& Compulsivity, 20(1-2), 65-78. doi:10.1080/10720162.2013. 768126
World Health Organization. (2018). ICD-11 Beta Draft. Mental, behavioural or neurodevelopmental disorders. Retrieved February 13, 2018, from https://icd.who.int/dev11/1-m/en

Young, K. S. (1998). Caught in the Net: How to recognize the signs of Internet addiction and a winning strategy for recovery. New York, NY: Wiley. 


\section{APPENDIX}

Table A1. Spanish version of the Sexual Addiction Screening Test (SAST)

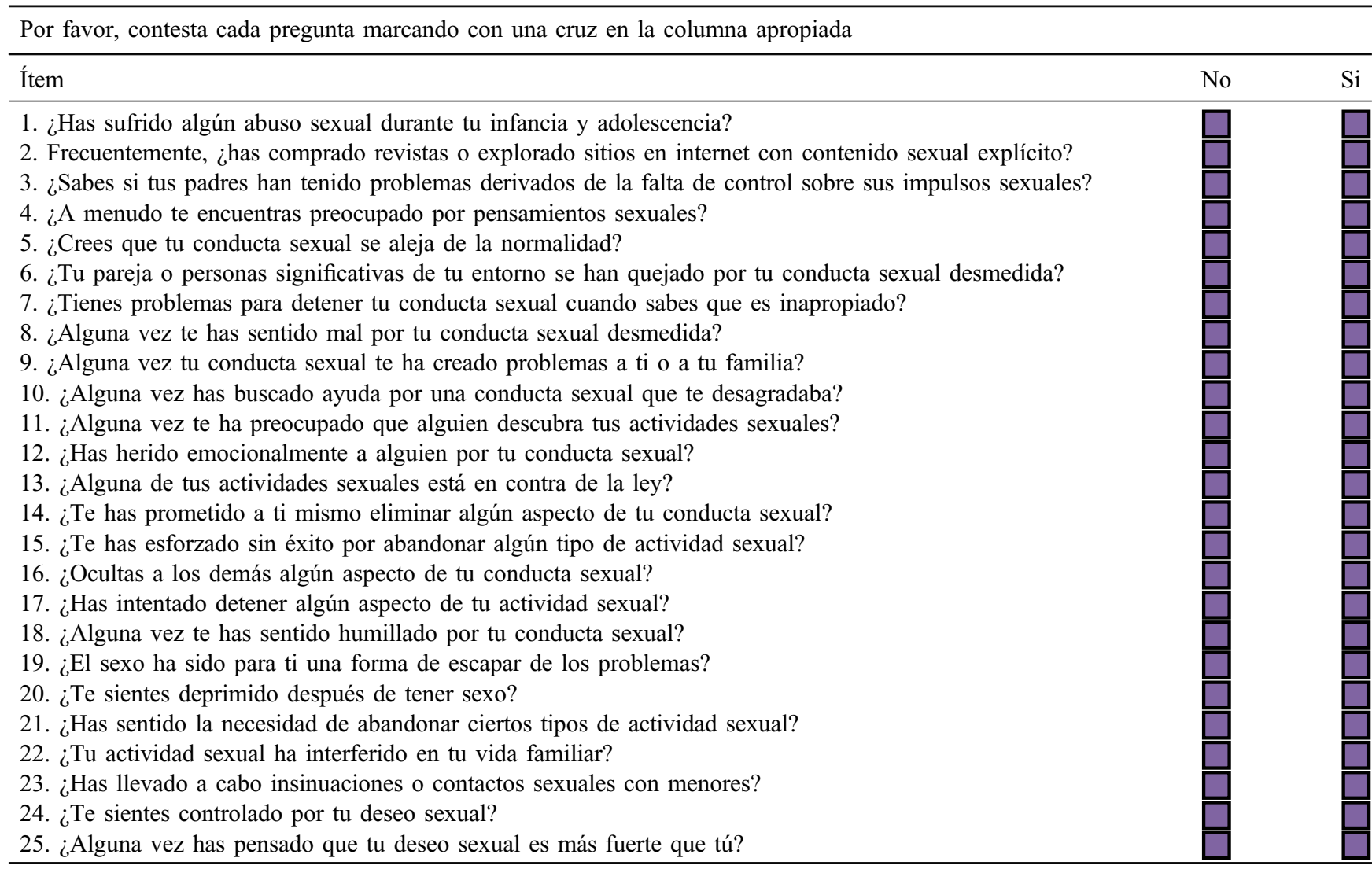

Table A2. Percentile distribution of the SAST scores

\begin{tabular}{lcc}
\hline & \multicolumn{2}{c}{ SAST score } \\
\cline { 2 - 3 } Percentile & Paper and pencil & Online \\
\hline 99th & 15 & 22.5 \\
95th & 11 & 13 \\
90 th & 9 & 10 \\
85th & 7 & 9 \\
80th & 6 & 7 \\
75th & 5 & 6 \\
70th & 5 & 5 \\
65th & 4 & 4 \\
60th & 3 & 4 \\
55th & 3 & 3 \\
50th & 2 & 3 \\
45th & 2 & 2 \\
40th & 2 & 2 \\
35th & 1 & 1.4 \\
30th & 1 & 1 \\
25th & 1 & 1 \\
20th & 0 & 1 \\
15th & 0 & 0 \\
10th & 0 & 0 \\
5th & 0 & 0 \\
1st & 0 & 0 \\
\hline
\end{tabular}

